\title{
Deformation and Compressive Strength of Steel Fiber Reinforced MgO Concrete
}

\author{
Feifei Jiang ${ }^{1,2}, * \mathbb{D}$, Zhongyang Mao ${ }^{1}$, Min Deng ${ }^{1}$ and Dawang $\mathrm{Li}^{2}$ \\ 1 State Key Laboratory of Materials-Oriented Chemical Engineering, College of Materials Science and \\ Engineering, Nanjing Tech University, Nanjing 211800, China; mzy@njtech.edu.cn (Z.M.); \\ dengmin@njtech.edu.cn (M.D.) \\ 2 College of Naval Architecture Civil Engineering, Jiangsu University of Science and Technology, \\ Zhangjiagang Campus, Suzhou 215600, China; zhjie@just.edu.cn \\ * Correspondence: $999620140019 @$ just.edu.cn
}

Received: 21 October 2019; Accepted: 1 November 2019; Published: 4 November 2019

Abstract: To reduce the cracking caused by shrinkage and avoid the brittle behavior of concrete, $\mathrm{MgO}$ expansion agent and steel fibers were used in this paper. Firstly, the effect of $\mathrm{MgO}$ and steel fibers on the compressive strength of concrete was compared. The results showed that the compressive strength of steel fibers reinforced concrete (SC) and steel fiber reinforced $\mathrm{MgO}$ concrete (SMC) was significantly improved. Compared with ordinary concrete (OC), SMC's 28 days compressive strength increased by $19.8 \%$. Secondly, the influence of $\mathrm{MgO}$ and steel fibers with different contents on the self-volumetric deformation of concrete was compared through the experiment. The results showed that as a result of the hydration expansion of $\mathrm{MgO}, \mathrm{MC}$ and $\mathrm{SMC}$ both showed obvious expansion, and their 190 days expansion was $335 \mu \varepsilon$ and $288 \mu \varepsilon$, respectively. Lastly, through a scanning electron microscope (SEM) test, it was found that the constraint effect of steel fibers changed the expansion mode of $\mathrm{MgO}$ from outward expansion to inward extrusion, thus improving the interfacial bond strength of concrete.

Keywords: concrete shrinkage; $\mathrm{MgO}$ expansion agent; steel fiber; compressive strength; self-volumetric deformation; interface structure

\section{Introduction}

Owing to its high compressive strength, good corrosion resistance, low price, and excellent operating performance, concrete has become the most popular building material all over the world. However, crack is a fatal flaw in concrete, which not only reduces the mechanical properties of concrete, but also provides channels for the intrusion of harmful substances in the outside world. Moreover, cracks accelerate the corrosion and destruction of concrete and seriously affect the durability of concrete, especially in ports and Marine structures.

In order to restrain concrete cracking and enhance its durability, researchers have proposed three methods. One is to compensate for shrinkage of cement-based materials during hydration by adding expansion agents, such as CaO-type, $\mathrm{MgO}$-type, and AFt-type expansion agents, which can reduce shrinkage cracks [1-5]. The other is to improve the crack resistance of concrete by adding fibers, such as polypropylene (PP) fibers, polyvinyl alcohol (PVA) fibers, and steel fibers, which can reduce plastic cracks and improve the ductility of concrete [6-9]. However, there are some shortcomings in these two methods. They can reduce shrinkage cracks by using an expansion agent, but they have no effect on cracks under load. What is more, only after concrete cracks can fibers play a bridge role, and they can only refine cracks, but not prevent them from occurring $[10,11]$. For fiber-reinforced expansive concrete, with concrete as a carrier, an expansion agent as the expansive element, and three-dimensional fibers 
distributed randomly as constraints, composite materials are assembled. This method can overcome the shortcomings of expansion agent and fiber used alone and give full play to the two advantages. Besides, it can even produce the "superposition" effect, effectively improving the crack resistance of concrete [12-15].

In the past two decades, some researches have focused on the engineering application of fiber-reinforced concrete and expansive concrete, such as railway sleepers [16-18], dams [19], and airport pavements [20]. In these studies, Ahsan Parvez proposed a method to improve the physical performance of the concrete sleeper such as durability, energy absorption, fatigue, and tolerance with the inclusion of steel fibers, and he found that a minimum volume of fibers $(0.25 \%)$ was essential to ensure enhanced performance [16]. Kaijian Huang proposed a method to enhance the volume stability of airport pavements in high altitude localities by adding fibers and $\mathrm{MgO}$ expansion agent [20].

In this paper, the authors combined $\mathrm{MgO}$ expansion agent with steel fibers. The expansion behavior of $\mathrm{MgO}$ is restrained by steel fibers in the hardening process and produces self-pressure, which can significantly improve the cracking load. The large vertical pressure exists at the interface between the cement matrix and steel fibers, which significantly improves the bonding property. Compared with polypropylene (PP) fibers and polyvinyl alcohol (PVA) fibers, steel fibers have a higher modulus of elasticity, and thus have stronger binding capacity, which can significantly improve the bonding property.

Owing to the constraints of steel fibers, the expansion and mechanical properties of steel fiber-reinforced $\mathrm{MgO}$ concrete (SMC) are quite different from those of $\mathrm{MgO}$ concrete (MC). In this paper, self-volumetric deformation experiments and compressive experiments were performed to reveal the expansion property of MC and SMC and the mechanical properties of SMC, which can help us understand SMC better and provide a theoretical basis for further engineering application.

\section{Materials and Experiments}

\subsection{Materials}

Portland cement, fly ash, coarse aggregates, fine aggregates, steel fibers, and polycarboxylate based plasticizer were used as the experimental objects. The details about each material are enumerated below.

\subsubsection{Cement}

The cement was produced by Shandong Shan Aluminum Cement Co., Ltd. (Zibo, China). The specific model was Shan Lu P.0. 52.5 ordinary Portland cement. The 3 days compressive strength of cement was $33.2 \mathrm{MPa}$ and the 28 days was $59.8 \mathrm{MPa}$. The initial setting time of cement was 220 $\mathrm{min}$, and the ultimate setting time was approximately $290 \mathrm{~min}$. Table 1 shows the detailed chemical composition of the cement.

Table 1. Chemical composition of cement.

\begin{tabular}{ccccccccccc}
\hline \multirow{2}{*}{ Type } & \multicolumn{10}{c}{ Chemical Composition/wt \% } \\
\cline { 2 - 11 } & $\mathrm{CaO}$ & $\mathrm{MgO}$ & $\mathrm{Al}_{2} \mathrm{O}_{3}$ & $\mathrm{SiO}_{2}$ & $\mathrm{Fe}_{2} \mathrm{O}_{3}$ & $\mathrm{SO}_{3}$ & $\mathrm{~K}_{2} \mathrm{O}$ & $\mathrm{Na}_{2} \mathrm{O}$ & Loss & Total \\
\hline Cement & 60.51 & 2.18 & 6.34 & 22.02 & 3.05 & 1.86 & 0.47 & 0.23 & 1.96 & 98.62 \\
\hline
\end{tabular}

\subsubsection{Fly Ash}

Fly ash was Class I fly ash produced by Shenhua Huashou Power Co., Ltd. (Shanghai, China). The sulfur trioxide content of fly ash was $1.2 \%$ and the water storage ratio was $74 \%$. Table 2 shows the detailed chemical composition of the fly ash. 
Table 2. Chemical composition of fly ash.

\begin{tabular}{ccccccccccc}
\hline \multirow{2}{*}{ Type } & \multicolumn{10}{c}{ Chemical Composition/wt \% } \\
\cline { 2 - 11 } & $\mathrm{CaO}$ & $\mathbf{M g O}$ & $\mathrm{Al}_{2} \mathbf{O}_{3}$ & $\mathrm{SiO}_{2}$ & $\mathrm{Fe}_{\mathbf{2}} \mathrm{O}_{\mathbf{3}}$ & $\mathrm{SO}_{3}$ & $\mathbf{K}_{\mathbf{2}} \mathrm{O}$ & $\mathbf{N a}_{\mathbf{2}} \mathrm{O}$ & Loss & Total \\
\hline Fly ash & 5.01 & 1.03 & 34.18 & 48.91 & 5.22 & 1.20 & 0.89 & 0.62 & 1.50 & 98.56 \\
\hline
\end{tabular}

\subsubsection{Steel Fiber}

Steel fibers were wavy steel fibers produced by Shuanglian Building Materials Co. LTD in Zibo, China and the tensile strength of the steel fibers was $520 \mathrm{MPa}$. The diameter of the steel fibers was 0.58 $\mathrm{mm}$ and the length was $38 \mathrm{~mm}$. The photograph of the wavy steel fibers utilized in the present study is depicted in Figure 1.

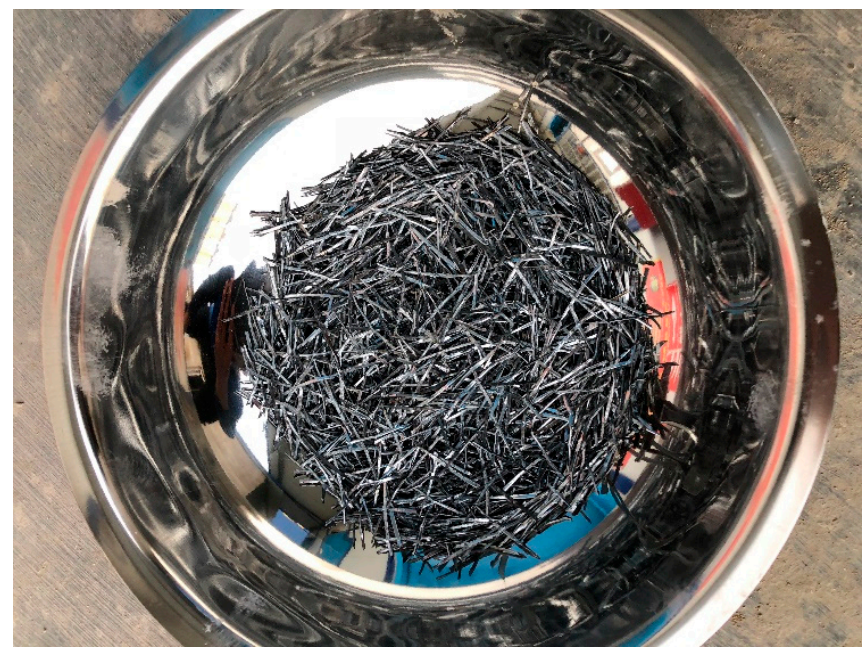

Figure 1. Photograph of wavy steel fibers.

\subsection{4. $\mathrm{MgO}$ Expansion Agent}

$\mathrm{MgO}$ expansion agent was produced by Wuhan Sanyuan Special Building Materials co. LTD in Wuhan, China, and its activity was $115 \mathrm{~s}$. The crystal size of MEA was $36.3 \mathrm{~nm}$ and the specific surface area was $45.7 \mathrm{~m}^{2} / \mathrm{g}$. The photograph of $\mathrm{MgO}$ in the present study is depicted in Figure 2. Table 3 shows the detailed chemical composition of $\mathrm{MgO}$.

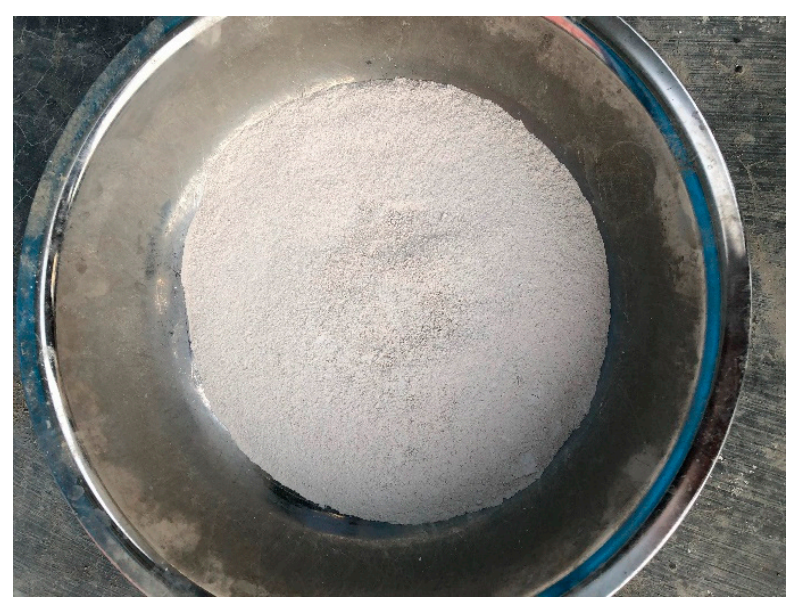

Figure 2. Photograph of $\mathrm{MgO}$. 
Table 3. Chemical composition of $\mathrm{MgO}$.

\begin{tabular}{cccccccc}
\hline \multirow{2}{*}{ Type } & \multicolumn{7}{c}{ Chemical Composition/wt \% } \\
\cline { 2 - 8 } & $\mathrm{CaO}$ & $\mathbf{M g O}$ & $\mathbf{A l}_{\mathbf{2}} \mathbf{O}_{\mathbf{3}}$ & $\mathrm{SiO}_{\mathbf{2}}$ & $\mathbf{F e}_{\mathbf{2}} \mathbf{O}_{3}$ & Loss & Total \\
\hline $\mathrm{MgO}$ & 3.19 & 85.44 & 0.73 & 4.45 & 0.42 & 4.49 & 98.72 \\
\hline
\end{tabular}

\subsubsection{Mix Proportions}

The mix proportions used in the present study are listed in Table 4. The content of $\mathrm{MgO}$ expansion agent was $8 \%$ of the total amount of cementitious materials, by weight. Besides, the content of steel fibers was $1 \%$, by volume.

Table 4. Mix proportion of concrete.

\begin{tabular}{|c|c|c|c|c|c|c|c|c|c|}
\hline \multirow[b]{2}{*}{ Specimen } & \multicolumn{8}{|c|}{ Composition/kg $\cdot \mathrm{m}^{-3}$} & \multirow[b]{2}{*}{$\mathbf{W} / \mathrm{C}$} \\
\hline & Cement & Fly Ash & $\begin{array}{c}\text { Fine } \\
\text { Aggregate }\end{array}$ & $\begin{array}{c}\text { Coarse } \\
\text { Aggregate }\end{array}$ & Water & $\begin{array}{c}\text { Water } \\
\text { Reducer }\end{array}$ & $\begin{array}{l}\text { Steel } \\
\text { Fiber }\end{array}$ & $\mathrm{MgO}$ & \\
\hline ordinary concrete $(\mathrm{OC})$ & 450 & 50 & 713 & 1025 & 160 & 6 & 0 & 0 & 0.32 \\
\hline $\mathrm{MgO}$ concrete (MC) & 450 & 50 & 713 & 1025 & 160 & 7.5 & 0 & 40 & 0.32 \\
\hline $\begin{array}{l}\text { steel fiber-reinforced } \\
\text { concrete (SC) }\end{array}$ & 450 & 50 & 713 & 1025 & 160 & 6 & 78 & 0 & 0.32 \\
\hline $\begin{array}{l}\text { steel fiber-reinforced } \\
\mathrm{MgO} \text { concrete (SMC) }\end{array}$ & 450 & 50 & 713 & 1025 & 160 & 7.6 & 78 & 40 & 0.32 \\
\hline
\end{tabular}

\subsection{Experimental Works}

\subsubsection{Strain Gauge}

Type-VWS-10 vibrating wire strain gauges made by Nanjing Gelan Industrial Co., Ltd. (Najing, China) were used. The gauge distance of strain gauge was $100 \mathrm{~mm}$, and the vibrating modulus of the strain gauge, $\mathrm{F}$, was closely related to its length, varying with the length change of the transducer brought about by deformation of concrete [20]. The strain was calculated by Equation (1):

$$
\varepsilon=k \Delta F+(b-a) \Delta T
$$

where $\varepsilon$ is the self-volumetric deformation of concrete; $k$ is measurement sensitivity of strain gauge; $\Delta F$ is the change in the measured value in real time relative to the base value of vibrating modulus; $b$ is temperature correction factor of strain gauge; $\mathrm{a}$ is the linear expansion coefficient of concrete; and $\Delta T$ is the change of the temperature.

\subsubsection{Experiment Works}

For each mix design, nine cylinders (dimension $\varnothing 50 \mathrm{~mm} \times \mathrm{H} 100 \mathrm{~mm}$ ) were cast for the measurements of compressive strength (ASTM C109 [21]), at 3 and 28 days after casting. In addition, four plastic buckets were used to test the self-volumetric deformation of concrete. The size of each plastic bucket was $\varnothing 250 \mathrm{~mm} \times 300 \mathrm{~mm}$ (Figure 3). The concrete was poured into a plastic bucket and the strain gauge was placed vertically in the bucket at the same time. Then, the concrete surface was sealed with epoxy resin to prevent moisture exchange. After that, the plastic bucket was moved to a 20 degree curing room to maintain a constant temperature and absolute humidity (Figure 4). All test preparations were to be completed within $20 \mathrm{~min}$. Lastly, the strain of concrete was tested every hour to research the self-volumetric deformation of concrete. 


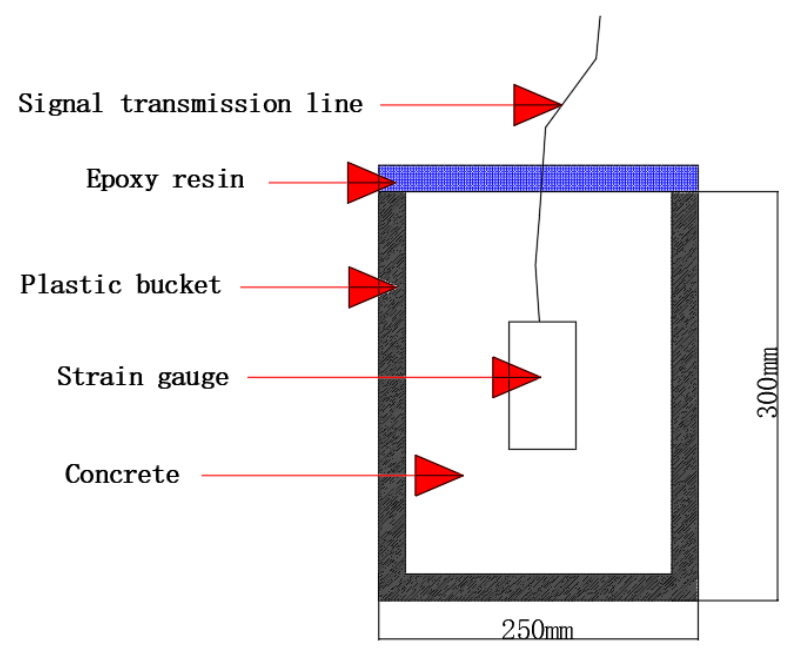

Figure 3. Schematic diagram of measuring device using strain gauge.

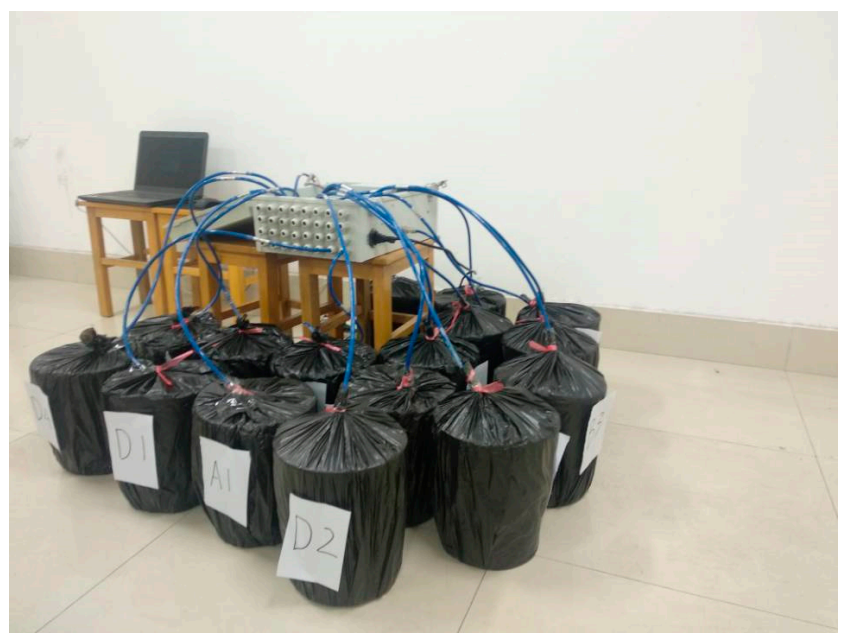

Figure 4. Self-volumetric deformation testing device for concrete.

\subsubsection{Microstructure Characterization}

In order to study the effect of the steel fibers and $\mathrm{MgO}$ expansion agent on the microstructure of concrete, fractured surfaces of concrete at the age of 30 days were investigated by scanning electron microscope (SEM, JSM-6510LA, JEOL, Ltd., Tokyo, Japan).

\section{Results and Discussion}

\subsection{Failure Pattern of Concrete}

The process of concrete compression failure is actually the process of crack generation, crack propagation, and crack penetration. In the process of loading, each specimen had experienced the elastic stage, elastic-plastic stage, and failure stage. Figure 5 shows the different failure modes of four different concrete specimens at 28 days. The failure modes of OC and MC specimens were brittle failure. Before the failure, a main crack first appeared on the surface of the specimen, with a wide width and few associated cracks. Moreover, the main crack developed rapidly, and the angle between the inclined crack surface and the vertical line of the load was 60-70 degrees. 


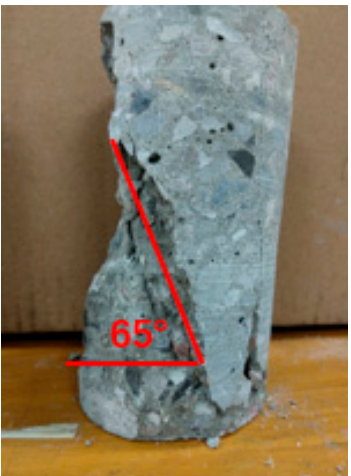

(a)OC

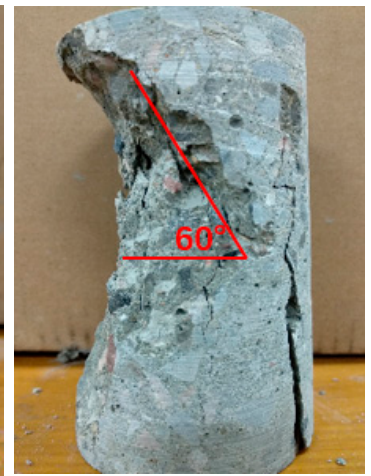

(b)MC

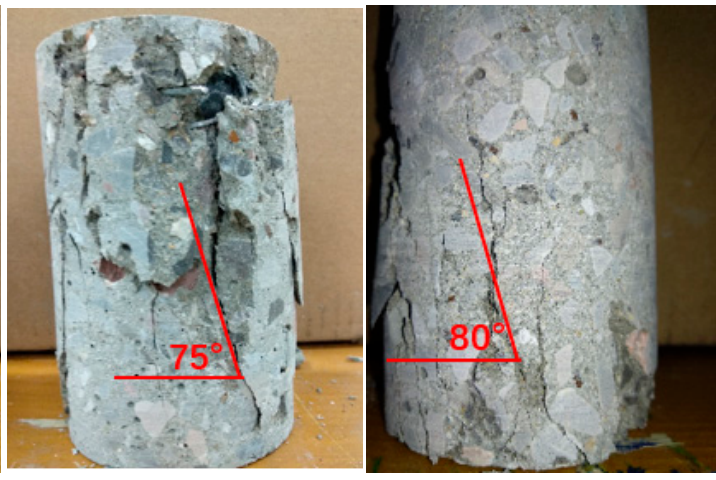

(c)SC

(d)SMC

Figure 5. Failure pattern of concrete. (a) OC, ordinary concrete; (b) MC, MgO concrete; (c) SC, steel fiber-reinforced concrete; (d) SMC, steel fiber-reinforced $\mathrm{MgO}$ concrete.

On the other hand, the failure modes of SC and SMC specimens were obviously brittle. When the specimen approached the peak stress gradually, a small number of small vertical cracks began to appear on the surface of the specimen. After reaching the peak point, the bearing capacity of the specimen decreased more and more slowly, and a large number of discontinuous longitudinal short cracks appeared. Finally, the specimen could not return to the original deformation state and formed an inclined main crack. The angle between the inclined crack surface and the vertical line of the load was 70-80 degrees, and the failure form of steel fibers was pull out failure.

\subsection{Compressive Strength of Concrete}

Figure 6 presents the results of the 3 days and 28 days compressive strength of the concrete specimens. For OC, the 3 days and 7 days compressive strength was $47.3 \mathrm{MPa}$ and $58.7 \mathrm{MPa}$, respectively. For $\mathrm{MC}$, the 3 days and 7 days compressive strength of concrete increased by $1.69 \%$ and $5.79 \%$ respectively, to $48.1 \mathrm{MPa}$ and $62.1 \mathrm{MPa}$. The reason for this increase is the addition of $\mathrm{MgO}$, which increases the total amount of active ingredients. For SC, the 3 days compressive strength of concrete decreased by $2.11 \%$, because the addition of steel fibers leads to an increase in the number of interfaces between fiber and cement matrix, and the 28 days compressive strength of concrete increased by $9.54 \%$, because the steel fibers have the effect of preventing crack development.

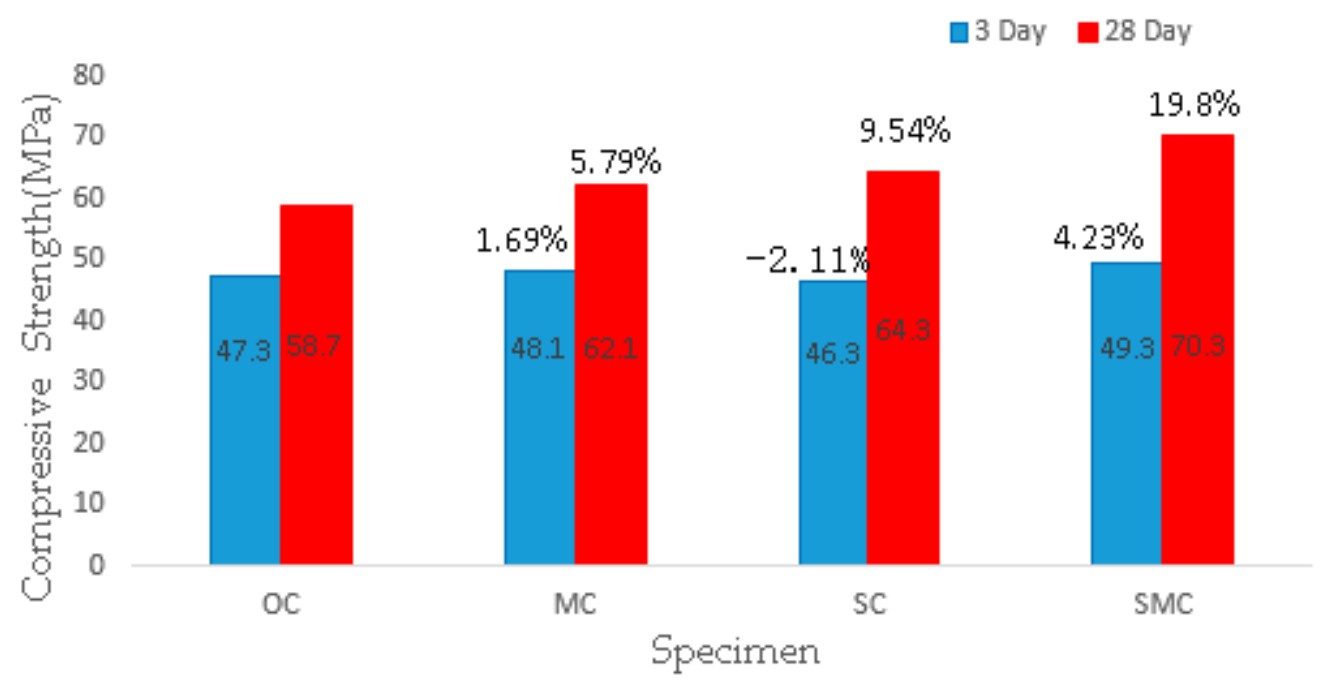

Figure 6. Compressive strength at 3 and 28 days. 
For SMC, the 3 days and 7 days compressive strength of concrete increased by $4.23 \%$ and $19.8 \%$ respectively, to $49.3 \mathrm{MPa}$ and $70.3 \mathrm{MPa}$. There are two main reasons for the rise in the strength of SMC. First, steel fibers prevent cracks from developing, and delay further damage to concrete. Secondly, the combined use of $\mathrm{MgO}$ and steel fibers produces a "superstack" effect and, under the constraint of steel fibers, and the stress of concrete becomes a three-way compression state, which create self-pressure inside the concrete and further increases the strength of the concrete.

\subsection{Deformations of Concrete}

The strain of concrete with different dosages of steel fibers and $\mathrm{MgO}$, which represents the self-volumetric deformation, is listed in Figure 7. For OC, its early shrinkage rate was relatively large (0-40 days), reaching $165 \mu \varepsilon$, after which the shrinkage rate was significantly reduced, and its 190 days shrinkage strain was $178 \mu \varepsilon$. For SC, its contraction curve was very similar to OC; however, different from OC, the late shrinkage of SC decreased significantly, and its 190 days shrinkage decreased by $24.1 \%$ to $135 \mu \varepsilon$. This means that steel fibers can improve the volumetric stability of concrete to some extent owing to the restraint effect of steel fibers. For $\mathrm{MC}$, the specimen showed an obvious expansion owing to the addition of $\mathrm{MgO}$, and the expansion value of 190 days reached $335 \mu \varepsilon$, which means that $\mathrm{MgO}$ can effectively compensate for the shrinkage of concrete. Because of the large shrinkage of concrete in the early stage ( $0-40$ days), the expansion of MC was small in the early stage and gradually increased in the late stage.

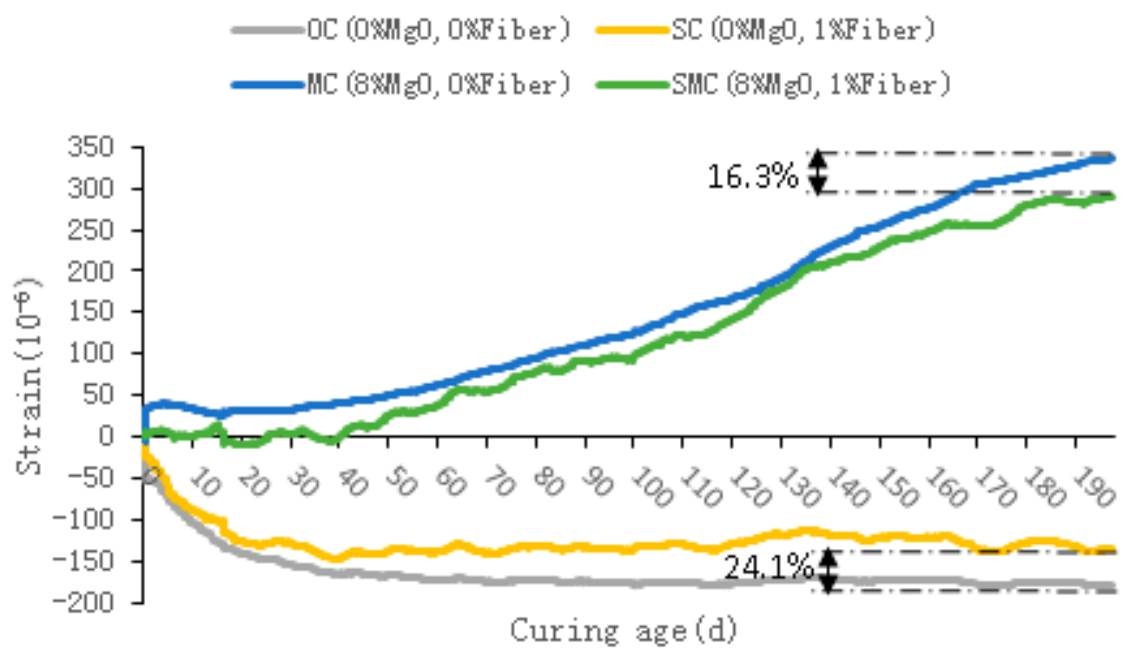

Figure 7. Self-volumetric deformation of concrete.

The expansion curve of SMC was similar to that of MC, but the 190 days expansion value of SMC was $16.3 \%$ less than that of MC owing to the constraint action of steel fibers, reaching $288 \mu \varepsilon$. In the first stage ( $0-50$ days), the SMC expansion energy was almost all used for tensioning steel fibers because of the strong constraint effect of steel fibers. Therefore, the total volume expansion of SMC was very small. The 50 days expansion was only $25 \mu \varepsilon$, which was $50 \%$ of the expansion of MC. After that, the expansion of SMC continued to increase as the restraint of the steel fibers weakened significantly, and both steel fibers and concrete matrix expanded outward together.

\subsection{Performance Enhancement Mechanism of Concrete}

\subsubsection{The Relationship between Expansion and Stress}

Figure 8 shows different expansion models of the concrete specimens. For expansion in the free state, the adjacent particles of MC move away from each other in a back direction, thus generating tensile stress in the concrete. What is more, in the process of concrete hardening, the compactness of 
concrete may be reduced owing to the existence of tensile stress. When the tensile stress exceeds the ultimate tensile stress of concrete, the concrete will crack. Therefore, when the expansion agent is used in excess, greater harmful expansion will also cause the concrete to crack [4]. On the other hand, for expansion under the constraint condition of steel fibers, the adjacent particles of SMC move in the opposite direction and get close to each other, so as to generate compressive stress in the concrete, that is, chemical pre-pressure, which indirectly improves the tensile strength of concrete.

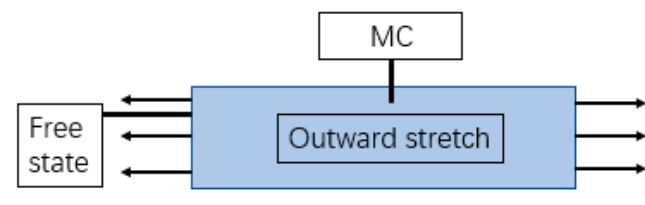

(a)

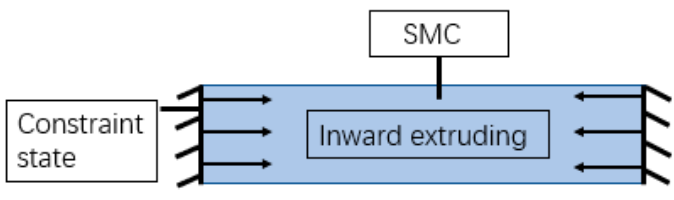

(b)

Figure 8. Expansion model of concrete: (a) Expansion under freedom, (b) Expansion under constraint.

\subsubsection{The Interface Structure of Concrete}

Concrete interface is the weak link of the concrete specimens, and the interface between cement matrix and aggregate directly affects the mechanical properties and durability of concrete [22-24]. Scanning electron microscope was performed to study the effect of steel fibers and $\mathrm{MgO}$ expansion agent on the interface. Figure 9 reflects the interface morphology of cement matrix and aggregate in concrete. For MC specimen in Figure 9a, there were many defects in the interfacial transition zone, long cracks in the parallel direction, and many associated cracks in the vertical direction. On the other hand, for SMC specimens in Figure 9b, because $\mathrm{MgO}$ and steel fibers act as extrusion fillers and pore refiners, a large vertical pressure exists at the interface between cement matrix and steel fibers, and the transition zone of SMC becomes very dense. In the vertical direction of SMC, only a few small cracks can be found, and the interface is intact, indicating that they have better interfacial bonding strength.

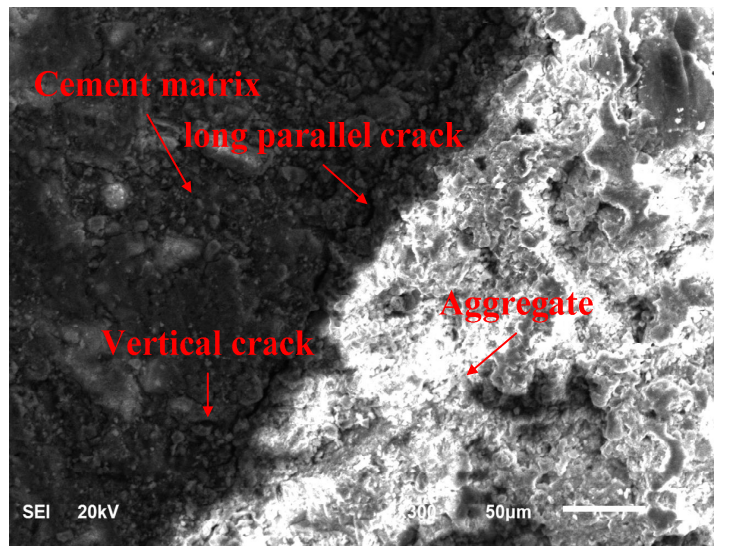

(a)

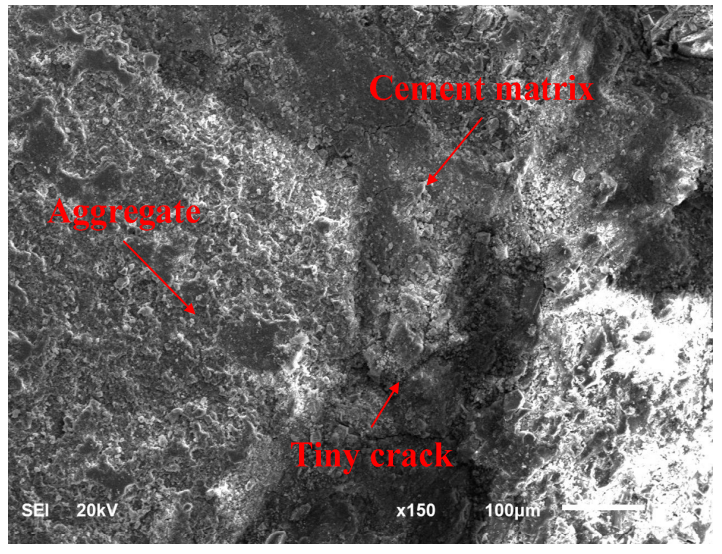

(b)

Figure 9. Scanning electron microscope (SEM) image of interface between cement matrix and aggregate: (a) MC, (b) SMC.

\section{Conclusions}

Considering the defects of $\mathrm{MgO}$ expansion agent or steel fibers when used alone, this paper combined $\mathrm{MgO}$ expansion agent and steel fibers. On the basis of detailed experiments and theories, the following conclusions can be drawn: 
(1) After the combined use of MgO expansion agent and steel fibers, the damage pattern of SMC under compression changed significantly compared with OC, and the SMC showed obvious ductile damage. The compressive strength of SMC increased by $19.8 \%$, which was much greater than the simple sum of strength increments of MC (5.79\%) and SC (9.54\%).

(2) Compared with OC, the 190 days shrinkage of SC was reduced by $24.1 \%$ owing to the restraint effect of steel fibers. However, the steel fibers cannot completely offset the shrinkage of the concrete, and the 190 days shrinkage of SC still reached $135 \mu \varepsilon$. Owing to the hydration of the MgO expansion agent, MC and SMC showed significant expansion, and their 190 day expansion was $335 \mu \varepsilon$ and $288 \mu \varepsilon$ respectively. Further, the steel fibers also restrained the expansion, causing the SMC's expansion to be $16.3 \%$ less than MC's.

(3) According to the SEM test, there were many defects in the interface between cement matrix and aggregate in $\mathrm{MC}$, while SMC had a denser interface and better bond strength, which explained why the compressive strength of SMC was significantly higher than MC.

(4) Thanks to the positive results in this study, SMC should be widely used in the basement, bridge deck, and other structures with high requirements for anti-seepage and crack resistance.

Author Contributions: F.J. designed and conducted the experimental program. M.D. gave many suggestions about experiment and helped solve the testing problems. Z.M. and D.L. assisted in pouring concrete. All authors assisted in the analysis.

Funding: This research was funded by Science and Technology Development Plan of Suzhou (SNG201904), Transportation Science and Technology Planning Project of Shandong Province (2018B37-02), and National Key Research and Development Plan of China (2016YFB0303601).

Acknowledgments: The authors would like to thank Liwu Mo from Nanjing Tech University for his precious contribution in the experiments.

Conflicts of Interest: The authors declare no conflict of interest.

\section{References}

1. Huang, K.; Shi, X.; Zollinger, D.; Mirsayar, M.; Wang, A.; Mo, L. Use of MgO Expansion Agent to Compensate Concrete Shrinkage in Jointed Reinforced Concrete Pavement Under High-Altitude Environmental Conditions. Constr. Build. Mater. 2019, 202, 528-536. [CrossRef]

2. Li, H.; Tian, Q.; Zhao, H.; Lu, A.; Liu, J. Temperature Sensitivity of MgO Expansion agent and its Application in Temperature Crack Mitigation in Shiplock Mass Concrete. Constr. Build. Mater. 2018, 170, 613-618. [CrossRef]

3. Chen, X.; Yang, H.; Li, W. Factors Analysis on Autogenous Volume Deformation of MgO Concrete and Early Thermal Cracking Evaluation. Constr. Build. Mater. 2016, 118, 276-285. [CrossRef]

4. Mo, L.; Deng, M.; Tang, M.; Al-Tabbaa, A. MgO Expansive Cement and Concrete in China: Past, Present and Future. Cem. Concr. Res. 2014, 57, 1-12. [CrossRef]

5. Dung, N.T.; Unluer, C. Carbonated MgO Concrete with Improved Performance: The Influence of Temperature and Hydration Agent on Hydration, Carbonation and Strength Gain. Cem. Concr. Compos. 2017, 82, 152-164. [CrossRef]

6. Alsaif, A.; Koutas, L.; Bernal, S.A.; Guadagnini, M.; Pilakoutas, K. Mechanical Performance of Steel Fibre Reinforced Rubberised Concrete for Flexible Concrete Pavements. Constr. Build. Mater. 2018, 172, 533-543. [CrossRef]

7. Liu, F.; Ding, W.; Qiao, Y. Experimental Investigation on the Flexural Behavior of Hybrid steel-PVA Fiber Reinforced Concrete Containing Fly Ash and Slag Powder. Constr. Build. Mater. 2019, 228, 116706. [CrossRef]

8. Akcay, B.; Ozsar, D.S. Do Polymer Fibers Affect the Distribution of Steel Fibres in Hybrid Fibre Reinforced Concretes? Constr. Build. Mater. 2019, 228, 116732. [CrossRef]

9. Shen, D.; Kang, J.; Yi, X.; Zhou, L.; Shi, X. Effect of Double Hooked-End Steel Fiber on Early-Age Cracking Potential of High Strength Concrete in Restrained Ring Specimens. Constr. Build. Mater. 2019, 223, 1095-1105. [CrossRef]

10. Chidighikaobi, P.C. Thermal Effect on the Flexural Strength of Expanded Clay Lightweight Basalt Fiber Reinforced Concrete. Mater. Today Proc. 2019. [CrossRef] 
11. Zhao, M.; Zhao, M.; Chen, M.; Li, J.; Law, D. An Experimental Study on Strength and Toughness of Steel Fiber Reinforced Expanded-Shale Lightweight Concrete. Constr. Build. Mater. 2018, 183, 493-501. [CrossRef]

12. Man, T.; Wang, B.; Jin, H.; Zhang, X. Expansion Behavior of Self-Stressing Concrete Confined by Glass-Fiber Composite Meshes. Constr. Build. Mater. 2016, 128, 38-46. [CrossRef]

13. Wang, B.; Man, T.; Jin, H. Expansive and Mechanical Properties of Textile Reinforced Self-Stressing Concrete. Constr. Build. Mater. 2015, 93, 1042-1050. [CrossRef]

14. Wang, B.X.; Jin, H.N.; Man, T. Study on Losses of Self-Stress Created by Steel Fiber Reinforced Self-Stressing Concrete. Appl. Mech. Mater. 2013, 438-439, 300-303. [CrossRef]

15. Wang, B.; Jin, H.; Man, T.; Wang, Q. Study on the Mechanical Property of Textile Reinforced Self-Stressing Concrete Sheets. Constr. Build. Mater. 2016, 107, 1-10. [CrossRef]

16. Parvez, A.; Foster, S.J. Fatigue of Steel-Fibre-Reinforced Concrete Prestressed Railway Sleepers. Eng. Struct. 2017, 141, 241-250. [CrossRef]

17. Yang, S.; Lim, Y. Mechanical Strength and Drying Shrinkage Properties of RCA Concretes Produced from Old Railway Concrete Sleepers Using by a Modified EMV Method. Constr. Build. Mater. 2018, 185, 499-507. [CrossRef]

18. Shin, H.; Yang, J.; Yoon, Y.; Mitchell, D. Mix Design of Concrete for Prestressed Concrete Sleepers Using Blast Furnace Slag and Steel Fibers. Cem. Concr. Compos. 2016, 74, 39-53. [CrossRef]

19. Gao, P.; Lu, X.; Geng, F.; Li, X.; Hou, J.; Lin, H.; Shi, N. Production of MgO-type Expansive Agent in Dam Concrete by Use of Industrial By-Products. Build. Environ. 2008, 43, 453-457. [CrossRef]

20. Huang, K.; Deng, M.; Mo, L.; Wang, Y. Early Age Stability of Concrete Pavement by Using Hybrid Fiber Together with MgO Expansion Agent in High Altitude Locality. Constr. Build. Mater. 2013, 48, 685-690. [CrossRef]

21. ASTM-C109/C109M-16a. Standard Test Method for Compressive Strength of Hydraulic Cement Mortars (Using 2-in. or [50-mm] Cube Specimens); ASTM International: West Conshohocken, PA, USA, 2016.

22. Selçuk, L.; Aşma, D. Experimental Investigation of the Rock-Concrete Bi Materials Influence of Inclined Interface on Strength and Failure Behavior. Int. J. Rock Mech. Min. Sci. 2019, 123, 104119. [CrossRef]

23. Shen, Y.; Wang, Y.; Yang, Y.; Sun, Q.; Luo, T.; Zhang, H. Influence of Surface Roughness and Hydrophilicity on Bonding Strength of Concrete-Rock Interface. Constr. Build. Mater. 2019, 213, 156-166. [CrossRef]

24. Xie, J.; Wei, M.; Huang, P.; Zhang, H.; Chen, P. Fatigue Behavior of the Basalt Fiber-Reinforced Polymer/Concrete Interface Under Wet-Dry Cycling in a Marine Environment. Constr. Build. Mater. 2019, 228, 117065. [CrossRef] 